RESEARCH REPORT

\title{
Validity of Antonovsky's sense of coherence scale: a systematic review
}

\author{
Monica Eriksson, Bengt Lindström
}

J Epidemiol Community Health 2005;59:460-466. doi: 10.1136/jech.2003.018085

See end of article for authors' affiliations

.....................

Correspondence to: Dr B Lindström, Nordic School of Public Health, Box 12133, S- 40242 Gothenburg, Sweden; bengt@nhv.se

Accepted for publication 18 January 2005

\begin{abstract}
Study objective: The aim of this paper is to systematically review and analyse the validity and reliability of Antonovsky's life orientation questionnaire/sense of coherence scale (SOC).

Design: The study is descriptive and analytical with a systematic integration of the contemporary knowledge base on the salutogenic research published 1992-2003. The review includes 458 scientific publications and 13 doctoral theses.

Setting: Worldwide, based on postgraduate scientific publications in eight authorised databases, doctoral theses, and available books.

Main results: The SOC questionnaire has been used in at least 33 languages in 32 countries with at least 15 different versions of the questionnaire. In 124 studies using SOC-29 the Cronbach's $\alpha$ ranges from 0.70 to 0.95 . The $\alpha$ values in 127 studies using SOC-13 range from 0.70 to 0.92 , and in 60 studies using a modified SOC scale range from 0.35 to 0.91 . Test-retest correlation show stability and range from 0.69 to 0.78 (1 year), 0.64 (3 years), 0.42 to 0.45 (4 years), 0.59 to 0.67 (5 years) to 0.54 (10 years). The means of SOC-29 range 100.50 (SD 28.50) to 164.50 (SD 17.10) points and SOC-13 from 35.39 (SD 0.10 ) to 77.60 (SD 13.80) points. After 10 years SOC seems to be comparatively stable, but not as stable as Antonovsky initially assumed. SOC tends to increase with age. The factorial structure of SOC seems rather to be multidimensional than unidimensional. SOC predicts a positive outcome in a long term perspective, although there are divergent findings reported. The SOC scale seems to be a reliable, valid, and cross culturally applicable instrument measuring how people manage stressful situations and stay well.
\end{abstract}

$M$ ore than 20 years have passed since the AmericanIsraeli medical sociologist Aaron Antonovsky introduced his salutogenic theory "sense of coherence" as a global orientation to view the world and the individual environment as comprehensible, manageable, and meaningful, claiming that the way people view their life has a positive influence on their health. ${ }^{1}$ Over the first 10 years after the introduction of the salutogenesis Antonovsky developed the life orientation questionnaire, sense of coherence scale, and examined its properties. In addition, the theory was somewhat revised over time and made more explicit in his second book Unraveling the Mystery of Health. ${ }^{2}$ The paradigm shift from the pathogenic focus on risk factors for disease to the salutogenic focus on the strengths and determinants for health was introduced. Fortigenesis, referring to the origins of one's psychological strength in general, attempts to broaden the SOC concept. ${ }^{3}$

Originally interviewing Israeli women about the adaptation to menopause Antonovsky studied a group with experiences from the concentration camps of the second world war who despite this stayed healthy. ${ }^{2}$ He was intrigued and raised the salutogenic question why these people were able to stay healthy. He postulated it was because of the way they viewed their life and their essence of existence. Through research three components emerged: the ability for people to understand what happens around them, to what extent they were able to manage the situation on their own or through significant others in their social network, and the ability to find meaning in the situation. These three elements, comprehensibility (cognitive), manageability (instrumental/ behavioural), and meaningfulness (motivational), formed the concept of sense of coherence. Another concept introduced were general resistance resources (GRR), ${ }^{1}$ such as material, ego identity, knowledge, intelligence, coping strategy, social support, commitment, cultural stability, magic, religion/philosophy, and a preventive health orientation. The GRRs are shaped by life experiences characterised by consistency, participation in shaping outcome, and a balance between underload and overload. ${ }^{2}$ These resources reinforce the SOC. Persons with a strong SOC are likely to identify a greater variety of GRRs at their disposal. ${ }^{4}$ Antonovsky emphasises that the SOC concept is a dispositional orientation rather than a personality trait/type or a coping strategy. ${ }^{4}$ The SOC construct reflects a person's capacity to respond to stressful situations.

In 1993 Antonovsky summarised the research until 1992 reporting data from 42 studies using the life orientation questionnaire/sense of coherence. ${ }^{2}$ Thereafter, unfortunately only a few researchers have reviewed results from studies on the SOC concept. However, these are only based on highly selected materials such as two Swedish reviews, ${ }^{56}$ unpublished material reviewing South-African studies, ${ }^{7}$ and a German review. ${ }^{8}$ The latter is hard to evaluate as it lacks clear inclusion criteria and a systematic methodology.

Since 2003 the Nordic School of Public Health has been running a salutogenic project. The main objective is to provide a more comprehensive understanding of the SOC concept by systematically reviewing, analysing, and synthesising the evidence on the salutogenic concept 1992-2003. So far and to our knowledge, this review is the first comprehensive attempt to review the whole area of salutogenic research after Antonovsky's sudden and unexpected death.

This paper is part of a more extensive review of the research area undertaken by the authors. The aim of this paper is to show the validity and the reliability of Antonovsky's SOC scale.

Abbreviations: SOC, sense of coherence scale; GRR, general resistant resources 


\section{METHOD}

This research synthesis focuses on empirical studies of the SOC scale and seeks to summarise, analyse, and present the state of knowledge on the salutogenic concept 1992-2003. ${ }^{10}$ The study is systematic in the sense that all included papers (see appendix, tables 9 and 10 (available on the journal web site http://www.jech.com/supplemental) ) have been critically examined according to a defined set of criteria. In the analysis the following dimensions have been applied: (1) the study objective (as the exploration of how SOC may effect health both as a dependent and an independent variable, the examination of predicting and maintaining value of the SOC regarding health, quality of life and wellbeing, the test of related measures to SOC, the exploration of the relation to different areas of life, the development of the theory base), (2) the study designs and methods for analysis, and (3) the applicability and practical use of the results. Studies using interviews for gathering data and quantitative methods for the analysis are categorised as quantitative studies.

\section{Inclusion and exclusion criteria}

The inclusion criteria are: (1) papers dealing with the SOC concept and/or using some of the different versions of the SOC questionnaire published in scientific peer reviewed journals; (2) postgraduate papers and doctoral thesis; (3) quantitative, qualitative, and intervention studies with equal weight to the method used; (4) papers in English, Finnish, Danish, Norwegian, and Swedish; (5) papers with a careful description of the translation process to other languages than English; (6) quantitative studies with an acceptable reliability and validity (face, consensual, construct, criterion, predictive, and responsiveness); (7) publication in the time span 19922003. Completing knowledge has been acquired from the authors.

Excluded are: (1) papers not using Antonovsky's life orientation questionnaire (SOC) for measuring coherence, (2) papers in other languages than the above mentioned (French, German, Japanese, Polish), (3) double published papers, (4) papers without references to Antonovsky's SOC concept (primary or secondary references), (5) papers with weakness in power-that is, response rate $<50 \%$ without a careful analysis of drop outs (after our request of completing information from the authors without an answer), (6) papers with insufficient validity of the SOC scale (that is, dealing only with one or two dimensions of the concept), (7) papers on master of science level or lower. Statistical data are systematically compiled (see appendix tables 2 to 8 ).

\section{Search strategy}

The search strategy is based on: (1) electronical search in the following databases PubMed (Medline), Bibsys, ISI, Libris, PsychInfo, Cinahl, Social Services Abstracts, Sociological abstracts, (2) search on the key words salutogenesis, salutogenic, sense of coherence, Antonovsky (also the Swedish and Finnish translations of sense of coherence), (3) reviewing reference lists in identified papers, (4) personal communication with the authors and colleagues.

\section{Material and procedure}

Description of the material is presented in a flow chart (see appendix, table 1). After adjustment for double listing in the databases and doctoral theses 458 hits met the inclusion criteria (as of 31 December 2003). The review is based on these articles and 13 doctoral theses (see appendix tables 9 and 10). In addition some other relevant books on this topic are included. We have been aware of the potential limitation of this analysis - that is, papers in other languages than the before mentioned-but we still assume the material is adequate enough for a reasonable review.
A detailed protocol was compiled for each article or doctoral thesis. This included details on (1) the aim (general papers on theoretical and philosophical considerations; validity of the SOC scale, association with health and health behaviour, coping with stress/work conditions, life events, disability, serious disease, association with quality of life and wellbeing, applicability in practice, learning, and association with social support and social network), (2) the country, (3) the sample (randomised, consecutive/convenience, matched), (4) the method/study design, (5) the ethical considerations, (6) the methods for analysis, (7) the version of the SOC questionnaire used, (8) the language of the SOC scale, (9) statistical data such as the population size, population mean age and sex, SOC means, standard deviation, Cronbach's $\alpha$, response rate, SOC division (low/weak compared with high/ strong), correlation with other standardised measures, (10) the main results and limitations of the study, (11) the references, (12) the author's contact data, (13) the key words related to details in the paper, (14) the comments of the assessment, and (15) the number related to the total reference list of included papers in the review (appendix table 9 and 10). The analysis is based on these protocols.

Furthermore, data were put together in tables on statistical data using SOC-29, SOC-13, modified versions of the SOC questionnaire (see appendix, tables 2 to 4 ), and on means and standard deviations of subscales (see appendix, table 5). In addition, SOC was compared with other standardised measures serving as tests of criterion validity, which are used in the different empirical studies, and categorised as follows: (1) health, (2) generalised perceptions of self and environment, (3) perceived stressors, (4) quality of life and wellbeing, (5) attitudes and behaviours (see appendix, table 4). Table 5 in the appendix follows the same structure and use the same division and classification as Antonovsky in his only review. ${ }^{4}$ This makes it easier to compare the data over time.

It was not possible to carry out a full meta-analysis mainly because of the great diversity of the base material and the variations in methods. The review material includes studies of varying sizes, samples, study design, and methods of analysis. Therefore we prefer to present the findings in tables and discuss the results. Validity is described and examined according to the classification in face, consensual, construct, criterion, predictive validity, and responsiveness. ${ }^{11}$ Reliability is examined through internal consistency measured by Cronbach's $\alpha$ and test-retest correlation.

\section{MAIN RESULTS Face validity}

The face validity of the SOC scale seems to be acceptable (see appendix, table 2-4). The respondents do not usually find the questionnaires difficult to complete (as an example no evidence that 80 year old or even older people have difficulties to complete the questionnaires. ${ }^{12}$ However, there are other experiences reported. Lee and colleagues found that Japanese respondents reported difficulties with filling in the scale compared with Chinese. ${ }^{13}$ The Chinese more often skipped questions. In a Swedish qualitative study on 15 Pentecostalists all the interviewees reported difficulties to answer the questions. ${ }^{14}$ The items concerning comprehensibility and manageability caused the most trouble. The strong ego-central items in the SOC questionnaire seemed to be inappropriate for these participants. These findings were not confirmed in another Swedish study among Pentecostalists. ${ }^{15}$ Problems with items 5, 6, 10, and 17 are reported. ${ }^{4} 1617$

Until 1993 the SOC questionnaire had been used in at least 14 languages (Afrikaans, Czech, Flemish/Dutch, English, Finnish, German, Hebrew, Norwegian, Rumanian, Russian, Serbian, Spanish, Swedish, Tswana). ${ }^{4}$ To date there are 
additional translations in at least 19 languages are found: Arabic, ${ }^{18}$ Bulgarian, ${ }^{19}$ Cambodian, ${ }^{20}$ Chinese ${ }^{13}{ }^{21-25}$ Danish, ${ }^{26-31}$ Dutch, $^{32}{ }^{33}$ Farsi, $^{34}{ }^{35}$ French, ${ }^{36}$ Greek, ${ }^{37} 38$ Icelandic, ${ }^{30}{ }^{39} 40$ Italian, ${ }^{41}$ Japanese, ${ }^{13}{ }^{42-46}$ Lithuanian, ${ }^{47}$ Polish, ${ }^{48}{ }^{49}$ Portuguese (Brazilian), ${ }^{50}{ }^{51}$ Sotho, ${ }^{52}$ Thai, ${ }^{53-55}$ Turkish, ${ }^{34}$ Slovenian. ${ }^{56}$ In total the SOC questionnaire has been used in 33 languages in 32 countries (Australia, Belgium, Brazil, Bulgaria, Canada, Czechia, ${ }^{4}$ China, Colombia, Denmark, Finland, France, Germany, Greece, Iceland, Israel, Japan, Lithuania, New Zealand, Netherlands, Norway, Poland, Rumania, ${ }^{4}$ Russia, Serbia, ${ }^{4}$ Singapore, Slovakia, South Africa, Sweden, Switzerland, Thailand, United Kingdom, USA) on subjects in studies varying from large samples of the general population covering 20000 persons to small samples about 20 people (for details see appendix tables 2 to 4 ). The SOC questionnaire has to date been used in both Western countries and countries such as Thailand, China, Japan, and South Africa. Therefore, the SOC scale seems to be a cross culturally applicable instrument.

Most of the studies are cross sectional, although some longitudinal ${ }^{17}{ }^{53}$ 57-74 studies were found. The study designs are either quantitative, qualitative, ${ }^{75-80}$ or intervention. ${ }^{6581-83}$ In the data collection questionnaires, interviews (or a combination of these two techniques), focus groups, or experience sampling method $\left(\mathrm{EMS}^{84}\right)$ have been used.

The means of SOC-29 range from 100.50 (SD 28.50) $)^{85}$ to 164.50 (SD 17.10) $)^{71}$ points (124 studies, see appendix table 2) and SOC-13 from $35.39(0.10)^{86}$ to $77.60(\text { SD 13.80) })^{12}$ points (127 studies, see appendix table 3 ). The mean values of the modified versions cannot be compared because of the diversity of the material (see appendix table 4).

\section{Consensual validity}

Consensual validity refers to the agreement of experts that a measure is valid. ${ }^{9}$ To date the consensual validity of the SOC scale seems to be moderate. Most of the studies used one of the original scales (SOC-29, SOC-13) in scientific disciplines like medicine/psychiatry/psychology, public health/health science, nursing, sociology, social work, and pedagogy. Until 1993 there were only a few attempts to modify the SOC questionnaire. ${ }^{4}$ However, the situation has completely changed today. Besides the original SOC questionnaire consisting of 29 items and the shorter version of 13 items there is an array of alternative instruments. At least 15 different versions exist with different scoring alternatives (including the two versions of the family sense of coherence scale $^{87-91}$ a questionnaire especially adjusted for children ${ }^{92-94}$ and the sense of school coherence instrument. $)^{95} 96$ The alternative instruments are: 3 items ${ }^{29-32} 343597-1036$ items, ${ }^{57} 737$ items, ${ }^{104} 9$ items, ${ }^{28}{ }^{58}{ }^{105-118} 10$ items, ${ }^{119} 11$ items, $^{41} 12$ items, ${ }^{120}$ 13 items (modified scoring alternatives), ${ }^{121-126} 16$ items, ${ }^{64} 127128$ 28 items, $^{65129}$ and 29 items $^{102}$ (modified scoring alternatives). In addition, 17 items and 19 items instrument were used before $1992 .{ }^{4}$ Furthermore, a 39 item SOC questionnaire is mentioned, perhaps this is a printing error. ${ }^{130}{ }^{131}$ Probably the same when talking about the original 28 item scale. ${ }^{118}$

The intercorrelation between the original SOC questionnaires and the alternatives are acceptable. The SOC-16 version, tested on 61 randomly selected Finns, showed a corresponding correlation of 0.87 with SOC-29. ${ }^{128}$ The reliability of the shortest form or SOC-3 measured by weighted $\kappa$ was $0.61 .{ }^{101}$

Antonovsky expressed that he wanted the SOC scale to be empirically examined before creating new modified scales. ${ }^{4}$ Unfortunately reality looks different. Besides the two original scales there are many modified versions in existence. The reasons are probably manifold. One explanation expressed is that the 29 item questionnaire sometimes seems to be too long, sometimes even the 13 items. An other argument for modifying the SOC questionnaire is to reach a better coherence with other measures used in the studies. ${ }^{132}$

\section{Construct validity}

The factorial structure of the scale in the three dimensions is not completely clear. Studies on whether the SOC scales actually correlate with the theoretical construction principles present differing results. Factor analysis has in some studies confirmed the one factor solution proposed by Antonovsky, ${ }^{133-136}$ while in others the analyses have failed to confirm this solution. ${ }^{48} 70137{ }^{138}$ A three factor and a second order factor model seemed to best fit the data on Finnish employees. ${ }^{139}$ Among 300 Swedish students a five factor solution was reported: meaning in life, control of feelings, negative feelings, trust/distrust, and changing future explaining $53 \%$ of the variance in SOC. ${ }^{140}$ More in line with Antonovsky are the findings from a Polish study on women staying in hospital after delivery. ${ }^{48}$ Here they found two main dimensions corresponding with meaningfulness and comprehensibility and three subdimensions. These factors accounted for $50 \%$ of the variance in SOC. The comprehensibility dimension seemed to consist of feelings of uncertainty, life events ordinary or surprisingly, and attitudes towards people. A three factor solution, but not the same as Antonovsky, is proposed by Sandell and colleagues on Swedish patients and controls. ${ }^{16}$ Here the meaningfulness component was interpreted as a zest/depression dimension, comprehensibility as intolerance compared with tolerance for emotional conflict. The third factor was only distantly related to manageability as interpersonal trust/mistrust. The three factor solution had a lower explanation power of less than $40 \%$ of the variance. ${ }^{16}$ SOC seems rather to be a multidimensional than a unidimensional concept.

Antonovsky's intention was to use the SOC questionnaire as a measurement of the whole not examining the three subscales separately. Despite this some studies report mean values regarding manageability, meaningfulness, and comprehensibility (see appendix, table 5). No general pattern emerges regarding the importance of the three dimensions.

Furthermore, he recommended the SOC concept to be examined without dividing the sum of the item values into low or high SOC. ${ }^{2}$ Consequently, he never expressed the level of a normal SOC. However, numbers of studies report divisions into low, moderate, or high SOC (see appendix, table 7). No general pattern of divisions emerges. Different researchers have used separate divisions.

Sex differences can be found. Men usually have a slightly higher SOC than women, although the differences are small (see appendix, table 6).

\section{Criterion validity}

Table 5 (see appendix) presents information about the relation between the SOC scale and other standardised instrument for measuring health, perceived self, stressors, quality of life, wellbeing, attitudes, and behaviours used in the studies. The extensive table follows the same structure and uses the same division and classification as Antonovsky in his only review, and gives detailed information on the existing different SOC instruments today. ${ }^{4}$ It would be possible and important to provide an extensive examination of the correlation and comparison of the different instruments. However, this falls beyond the scope of this paper.

Correlation below 0.20 is assessed as poor, between 0.20 0.35 slight, $0.35-0.65$ moderate, $0.65-0.85$ good, and above 0.85 very good. ${ }^{141}$ The correlation with health range in general from slight to good, using instruments such as the general health questionnaire, ${ }^{142}{ }^{143}$ health index, ${ }^{144}{ }^{145}$ Hopkin's symptom checklist, ${ }^{146}{ }^{147}$ or mental health inventory ${ }^{18}{ }^{148}$ explaining at highest $66 \%$ of the variance in SOC. Some correlations in 
table 5 are not significant. However, a p value in the nonsignificant range only tells that either there is no difference between groups or that there were too few subjects, but not which one. ${ }^{149}$ It is more important to examine the different values of the coefficients and the explained variance.

The relatively high negative correlation with anxiety and depression is striking, as is the strong positive correlation with optimism and self esteem. The moderate correlation with instruments measuring life events shows that SOC is related to changes in the individual environment. There are numbers of studies on the relation between SOC and quality of life and wellbeing. In general they show that a high SOC is related to a high quality of life. SOC seems also be connected with attitudes and behaviours.

\section{Predictive validity}

The capacity of the SOC scale to predict a future outcomethat is, health-is expressed by the predictive validity. ${ }^{11}$ Examining the longitudinal studies the findings show a comparatively high predictability, although there are divergent results reported. In a short term perspective of three months the SOC played an important part for discriminating people at risk for developing post-traumatic stress symptoms among survivors of the MS Estonia disaster. ${ }^{120}$ In patients with orthopaedic injuries ${ }^{150}$ and patients with morbid obesity $^{151}$ the SOC predicted a better outcome after surgery after one year. Support for the predictive validity of the SOC (18 month) is reported among schizophrenic patients. ${ }^{152}$ Having a comparatively high SOC was a predictor of a positive outcome among unemployed with a somatic disorder after two years (OR: 3.5, CI: 1.5 to 8.4). ${ }^{153}$ In a long term perspective (five years) the SOC had a very good predictive value for disability among Finnish patients. ${ }^{154}$ Kalimo and colleagues report findings from a 10 year follow up of Finnish employees, where SOC and changes in support from superior were the best predictors of burnout. ${ }^{74}$ However, there are other findings reported. In a group of Finnish municipal employees and technical designers the findings failed to support the SOC theory. Here predictive relations from health to SOC were not found. ${ }^{73}$

\section{Responsiveness}

The SOC seems to be comparatively stable over time, at least for people with an initial high SOC, but not as stable as Antonovsky assumed. The variation in means over time shows small differences. No differences or very small ones are reported in a three to five year perspective. ${ }^{61}{ }^{63-65}{ }^{73}$ However, the same situation emerges in a 10 year follow up study among Finnish employees. ${ }^{74}$ Furthermore, SOC tends to increase with age over the whole life span. Using SOC-29 items (based on the mean age of the cross sectional studies) the oldest people show the highest mean scores on SOCthat is, 18 year old American college students 131.00, ${ }^{155} 37$ year old French adults $133.60,{ }^{134}$ American older women (76 years) $157.21,{ }^{156}$ and 81 year old people $158.90 .{ }^{157}$

\section{Reliability}

\section{Internal consistency}

The internal consistency measured by Cronbach's $\mathrm{s}^{158} \alpha$ ranges from $0.70^{159}$ to $0.95^{160}$ using SOC-29 (124 studies, see appendix table 2 ), $0.70^{161}$ to $0.92^{154}$ ( 127 studies, see appendix table 3) using SOC-13. Among the modified versions of the SOC scale The EPIC-Norfolk United Kingdom prospective cohort study reports the lowest $\alpha$ of 0.35 using the shortest form of SOC-3. ${ }^{103}$ The highest $\alpha$ of $0.91^{102}$ is reported in a study using a modified scoring alternative of the original 29 item questionnaire ( 5 point Likert scale) (60 studies, see appendix table 4). Coefficients above 0.70 reflect good internal consistency. ${ }^{162}$ The SOC scale shows high internal consistency.

\section{Test-retest}

Antonovsky assumed the individual SOC was stabilised by the end of early adulthood. Thereafter the SOC fluctuates marginally. ${ }^{2}$ Very few longitudinal studies were undertaken before 1993. ${ }^{4}$ This means the longitudinal studies reporting test-retest reliability are few. Test-retest reliability of the scales range from 0.92 (one week), ${ }^{133} 0.65$ (three weeks), ${ }^{36}$ 0.93 (one month), ${ }^{133} 0.77$ (six months) ${ }^{72}$ using SOC-29. Fiorentino $^{70}$ reports a one year correlation range of 0.78 (SOC-29). Using SOC-13 the corresponding range is $0.69^{59}$ to $0.72^{17}$. Among Swiss adolescents the correlation was 0.77 after 18 months. ${ }^{59}$ However, the few longitudinal studies with an greater time span report correlations of 0.64 (three years), ${ }^{73} 0.42$ to .0 .45 (four years), ${ }^{62} 0.59$ to 0.67 (five years), ${ }^{72}$ and a 10 year correlation of 0.54 (personal communication with Pahkin December 2004). Such statistical data are in line with data reported by Antonovsky. ${ }^{4}$

\section{DISCUSSION}

The purpose of this paper was to review the validity and reliability of Antonovsky's SOC scale 1992-2003 as a part of a more extensive review on the salutogenic research. There is a need for a comprehensive understanding of the SOC concept. Therefore our attempt to make sense of the comprehensive research should be beneficial for further research. Furthermore, the extensive documentation of references serves as bibliography on the salutogenesis.

As of semantics some authors used the word salutogenetic to describe the concept. To our opinion salutogenic is a more preferable word, because the knowledge about how SOC might be related to genetic factors is not clear.

A full meta-analysis as method has not been used. Because of the diversity of the material we have adopted another approach and have tried to provide a research synthesis according to Cooper.' This could be seen as a limitation. Another limitation could be the choice of included languages, but despite the location of the studies most are published in English. We have checked the English abstracts of studies in other languages. Because they generally lack statistical data they are excluded from this paper.

The SOC scale has proved to be psychometrically comparatively sound. However, the structure of the SOC concept is still not completely clear. SOC seems to have a multidimensional character rather than a unidimensional. To our opinion there is at present no need for further testing of the SOC instrument because the findings prove the SOC instrument being reliable, valid, feasible, and cross culturally applicable. Furthermore, there is no need to develop new SOC versions. There is rather a need of consolidation and a standardisation of the instruments. It would be more relevant to develop qualitative methods.

SOC does not seem to be as stable as Antonovsky assumed. The evidence shows that SOC tends to increase with age through the whole life span. The older the age of the population sample the higher the SOC score. Whether the increases in the individual SOC are an effect of natural selection of people-healthy people survive-or a question of people developing a strong SOC staying well is not clear. We suggest the second explanation.

Some authors propose the SOC questionnaire could be used as a screening instrument aiming at the identification of people at risk of developing a low SOC. This is perhaps justified, but there is still the problem of interpreting the individual position on the health/ease and dis-ease continuum. It is not clear where SOC no longer protects the movement towards the healthy end. Knowledge about this is 
still incomplete. There is also a risk of negative health effects if one stigmatises people in groups regarding their SOC. What does the individual level of SOC at a given time really mean in practice? Therefore, we do not recommend the use of the SOC questionnaire as a screening instrument. Instead we suggest that the SOC concept could be implemented as a systematic orientation and perspective in the daily activities and actions of the professionals. There is a need to change focus from problems and obstacles to resources. The most important immediate research focus now would be to implement the theory in practice.

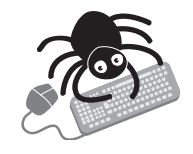

The appendix, papers used in the review, and the doctoral theses papers are available on the journal web site (http://www.jech.com/supplemental).

\section{Authors' affiliations}

M Eriksson, B Lindström, Nordic School of Public Health, Gothenburg, Sweden

Funding: this study was supported by grants from the European Commission (European Masters in Health Promotion, EUMAHP) and the Nordic School of Public Health.

Conflicts of interest: none.

\section{REFERENCES}

1 Antonovsky A. Health, stress and coping. San Francisco: Jossey-Bass, 1979

2 Antonovsky A. Unraveling the mystery of health. How people manage stress and stay well. San Francisco: Jossey-Bass, 1987.

3 Strümpfer D. The origins of health and strength: from "salutogenesis" to "fortigenesis". South African Journal of Psychology 1995;25:81-9.

4 Antonovsky A. The structure and properties of the sense of coherence scale. Soc Sci Med 1993;36:725-33.

5 Langius A, Biörvell $\mathrm{H}$. Salutogenic model and use of the wense of coherence scale in nursing research-a methodological report. Vård $i$ Norden 1996;16:28-32

6 Hansson K, Olsson M. Sense of coherence-a human endeavour. Nordisk Psykologi 2001;53:238-55

7 Strümpfer D, Wissing M. Review of South African data on the sense of coherence scale as a measure of fortigenesis and salutogenesis. Psychological Society of South Africa, Cape Town, Sep 1998

8 Bengel J, Strittmatter R, Willman H. What keeps people healthy? The current state of discussion and the relevance of Antonovsky's salutogenic model of health. Cologne: Federal Centre for Health Education (FCHE), 1999

9 Cooper H. Synthesizing research. A guide for literature review. 3rd ed. Thousand Oaks: Sage, 1998.

10 Hunt M. How science takes stock. The story of meta-analysis. New York Russell Sage Foundation, 1999.

11 Abramson JH, Abramson ZH. Survey methods in community medicine. Epidemiological research programme evaluation clinical trials. 5th ed. Edinburgh: Churchill Livingstone, 1999

12 Steiner A, Raube K, Stuck AE, et al. Measuring psychosocial aspects of wellbeing in older community residents: performanace of four short scales. Gerontologist 1996;36:54-62.

13 Lee JW, Jones PS, Mineayama Y, et al. Cultural differences in responses to a Likert scale. Res Nurs Health 2002;25:295-306.

14 Benzein E, Norberg A, Saveman B-I. Limitations of the sense of coherence scale in a Swedish Pentecostal population. Scandinavian Journal of Caring Science 1997;11:139-44.

15 Langius A, Biörvell $H$. The applicability of the Antonovskys sense of coherence scale to a group of Pentecostalists. Scandinavian Journal of Caring Science 2001;15:190-2.

16 Sandell R, Blomberg J, Lazar A. The factor structure of Antonovsky's sense of coherence scale in Swedish clinical and nonclinical samples. Personality and Individual Differences 1998;24:701-11.

17 Feldt T. Sense of coherence. Structure, stability and health promoting role in working life. Jyväskylä studies in education, psychology and social research. (Doctoral thesis.) Jyväskylä: University of Jyväskylä, 2000.

18 Cohen O, Savaya R. Sense of coherence and adjustment to divorce among Muslim Arab citizens of Israel. European Journal of Personality 2003; 17:309-26.

19 Dalbokova D, Tzenova B, Ognjanova V. Stress states in nuclear operators under conditions of shiftwork. Work and Stress 1995;9:305-13.

20 Ying Y-W, Akutsu PD, Zhang X, Huang LN. Psychological dysfunction in Southeast Asian refugees as mediated by sense of coherence. Am J Community Psychol 1997;25:839-59.

21 Shiu AT-Y. The significance of sense of coherence for the perceptions of task characteristics and stress during interruptions amongst a sample of public health nurses in Hong Kong: implications for nursing management. Public Health Nursing 1998;15:273-80.
22 Ying Y-W. Strengthening intergenerational/intercultural ties in migrant families: a new intervention for parents. Am J Community Psychol 1999;27:89-96.

23 Cai D, Giles H, Noels K. Elderly perceptions of communication with older and younger adults in China: implications for mental health. Journal of Applied Communication Research 1998;26:32-51.

24 Tang ST, Dixon J. Instrument translation and evaluation of equivalence and psychometric properties: the Chinese sense of coherence scale. J Nurs Meas 2002; 10:59-76.

25 Yam BMC, Shiu ATY. Perceived stress and sense of coherence among critical care nurses in Hong Kong: a pilot study. J Clin Nurs 2003;12:144-6.

26 Due EP, Holstein BE. "Sense of coherence", socialgruppe og helbred i en dansk befolkningsundersøgelse. Ugeskr Laeger 1998;160:7424-9.

27 Karlsson I, Rasmussen C, Ravn J, et al. Chest pain after coronary artery bypass: relation to coping capacity and quality of life. Scand Cardiovasc J 2002;36:41-7.

28 Albertsen K, Nielsen ML, V. Borg. The Danish psychosocial work environment and symptoms of stress: the main, mediating and moderating role of sense of coherence, Work and Stress 2001;15:241-53.

29 Avlund K, Vass M, Hendriksen C. Onset of mobility disability among community-dwelling old men and women. The role of tiredness in daily activities. Age Ageing 2003;32:579-84.

30 Berntsson L. Health and well-being of children in the five Nordic countries in 1984 and 1996. (Doctoral thesis.) Gothenburg: The Nordic School of Public Health, 2000.

31 Grøholt E-K, Stigum H, Nordhagen R, et al. Is parental sense of cohrence associated with child health? Eur J Public Health 2003;13:195-201.

32 Loon AJMv, Tijhuis M, Surtees PG, et al. Personality and coping: their relationship with lifestyle risk factors for cancer. Personality and Individual Differences 2001;31:541-53.

33 Gallagher TJ, Wagenfeld MO, Baro F, et al. Sense of coherence, coping and caregiver role overload. Soc Sci Med 1994;39:1615-22.

34 Bayard-Burfield L, Sundquist J, Johansson S-E. Ethnicity, self reported psychiatric illness, and intake of psychotropic drugs in five ethnic groups in Sweden. J Epidemiol Community Health 2001;55:657-64.

35 Sundquist J, Bayard-Bufield L, Johansson LM, et al. Impact of ethnicity, violence and acculturation on displaced migrants. Psychological distress and psychosomatic complaints among refugees in Sweden. J Nerv Ment Dis 2000;188:357-65.

36 Gana K, Garnier S. Latent structure of the sense of coherence scale in a French sample. Personality and Individual Differences 2001;31:1079-90.

37 Giotakos O. Suicidal ideation, substance use, and sense of coherence in Greek male conscripts. Mil Med 2003;168:447-50.

38 Tselebis A, Moulou A, llias I. Burnout versus depression and sense of coherence: study of Greek nursing staff. Nursing and Health Sciences 2001;3:69-71.

39 Svavarsdottir EK, McCubbin MA, Kane JH. Well-being of parents of young children with asthma. Res Nurs Health 2000;23:346-58.

40 Svavarsdóttir EK, Rayens MK. American and Icelandic parents' perceptions of the health status of their young children with chronic asthma. Journal of Nursing Scholarship 2003;35:351-8.

41 Wydler H, Walter T, Hättich A, et al. Die Gesundheit 20jähriger in der Schweitz. Ergebnisse der PRP 1993. Frankfurt am Main: Verlag Sauerländer, 1996

42 Nasermoaddeli A, Sekine M, Hamanishi S, et al. Job strain and sleep quality in Japanese civil servants with special reference to sense of coherence. Journal of Occupational Health 2002;44:337-42

43 Nakamura H, Ogawa Y, Nagase H, et al. Natural killer cell activity and its related psychological factor, sense of coherence in male smokers. Journal of Occupational Health 2001:43:191-8.

44 Nakamura H, Matsuzaki I, Sasahara S, et al. Enhancement of a sense of coherence and natural killer cell activity which occurred in subjects who improved their exercise habits through health education in the workplace. Journal of Occupational Health 2003;45:278-85.

45 Matsuura E, Ohta A, Kanegae F, et al. Frequency and analysis of factors closely associated with the development of depressive symptoms in patients with scleroderma. J Rheumatol 2003;30:1782-7.

46 Nasermoaddeli A, Sekine M, Hamanishi S, et al. Associations of sense of coherence with sickness absence and reported symptoms of illness in Japanese civil servants. Journal of Occupational Health 2003;45:231-3

47 Kristenson M, Kucinskienë Z, Bergdahl B, et al. Increased psychosocial strain in Lithuanian versus Swedish men: the LiVicordia study. Psychosom Med 1998;60:277-82.

48 Dudek B, Makowska Z. Psychometric characteristics of the orientation to life questionnaire for measuring the sense of coherence. Polish Psychological Bulletin 1993;24:309-18.

49 Dudek B, Koniarek J. Relationship between sense of coherence and posttraumatic stress disorder symptoms among firefighters. Int J Occup Med Environ Health 2000;13:299-305.

50 Freire MCM, Sheiham A, Hardy R. Adolescents' sense of coherence, oral health status, and oral health-related behaviours. Community Dent Oral Epidemiol 2001;29:204-12.

51 Freire MdCM, Hardy R, Sheiham A. Mothers' sense of coherence and their adolescent children's oral health status and behaviours. Community Dent Health 2002;19:24-31

52 Botha KF, Du Plessis WF, van Rooyen J, et al. Biopsychosocial determinants of self-management in culturally diverse South African patients with essential hypertension. Journal of Health Psychology 2002;7:519-31.

53 Nintachan P, Sompongse $P$. The sense of coherence and trait-anxiety of nursing students at Ramathibodi School of Nursing: a four year follow up 
study during academic year 1994-1997. Rama Nursing Journal 2000;6:119-32

54 Cederblad M, Pruksachatkunakorn P, Boripunkul T, et al. Behaviour problems and competence in Thai children and youths: teachers', parents' and subjects' perspectives. Transcultural Psychiatry 2001:38:64-79.

55 Cederblad M, Pruksachatkunakorn P, Boripunkul T, et al. Sense of coherence in a Thai sample. Transcultural Psychiatry 2003;40:585-600.

56 Ruiselová Z. Self-evaluation of coping in the context of personal intelligence. Studia Psychologica 1995; 37:149-53.

57 Kivimäki $M$, Elovainio $M$, Vahtera J, et al. Sense of coherence as a mediator between hostility and health. Seven-year prospective study on female employees. J Psychosom Res 2002;52:239-47.

58 Forsgärde $M$, Westman B, Nygren L. Ethical discussion groups as an intervention to improve the climate in interprofessional work with the elderly and disabled. Journal of Interprofessional Care 2000;14:351-61

59 Buddeberg-Fischer B, Klaghofer R, Schnyder U. Sense of coherence in adolescents. Soz Präventivmed 2001;46:404-10.

60 Feldt $\mathrm{T}$, Leskinen $\mathrm{E}, \mathrm{Kinnunen} \mathrm{U}$, et al. The stability of sense of coherence: comparing two age groups in a 5-year follow-up study. Personality and Individual Differences 2003;35:1151-65.

61 Nilsson B, Holmgren L, Stegmayr B, et al. Sense of coherence-stability over time and relation to health, disease, and psychosocial changes in a general population: a longitudinal study. Scand J Public Health 2003;31:297-304.

62 Smith PM, Breslin CF, Beaton DE. Questioning the stability of sense of coherence. The impact of socio-economic status and working conditions in the Canadian population. Soc Psychiatry Psychiatr Epidemio 2003;38:475-84.

63 Virtanen $P$, Koivisto A-M. Wellbeing of professionals at entry into the labour market: a follow up survey of medicine and architecture students. J Epidemiol Community Health 2001:55:831-5.

64 Suominen S, Helenius $\mathrm{H}$, Blomberg $\mathrm{H}$, et al. Sense of coherence as a predictor of subjective state of health. Results of 4 years of follow-up of adults. J Psychosom Res 2001; 50:77-86.

65 Kuuppelomäki M, Utriainen P. A 3 year follow-up study of health care students' sense of coherence and related smoking, drinking and physical exercise factors. Int J Nurs Stud 2003;40:383-8.

66 Cederfjäll C, Langius-Eklöf A, Lidman K, et al. Self-reported adherence to antiretroviral treatment and degree of sense of coherence in a group of HIVinfected patients. AIDS Patient Care and STDS 2002;16:609-16.

67 Karlsson I, Berglin E, Larsson PA. Sense of coherence: quality of life before and after coronary artery bypass surgery-a longitudinal study. J Adv Nurs 2000;31:1383-92

68 Pålsson M-B, Hallberg IR, Norberg A, et al. Burnout, empathy and sense of coherence among Swedish district nurses before and after systematic clinical supervision. Scandinavian Journal of Caring Science 1996;10:19-26.

69 Malmgren-Olsson E-B, Bränholm I-B. A comparison between three physiotherapy approaches with regard to health-related factors in patients with non-specific musculoskeletal disorders. Disabil Rehabil 2002;24:308-17.

70 Fiorentino LM. Sense of coherence and the stress-illness relationship among employees: a prospective study. In: McCubbin HI, Thompson TE, Thompson Al, et al, eds. Stress, coping, and health in families. Sense of coherence and resiliency. Thousand Oaks: Sage, 1998:91-106.

71 Zhang J, Vitaliano PP, Lutgendorf SK, et al. Sense of coherence buffers relationships of chronic stress with fasting glucose levels. J Behav Med 2001;24:33-55

72 Coe RM, Romeis JC, Hall MM. Sense of coherence and survival in the chronically ill elderly. A five-yar follow-up. In, McCubbin HI, Thompson EA, Thompson Al, et al, eds. Stress, coping, and health in families. Sense of coherence and resiliency. Thousand Oaks, Sage, 1998:265-75.

73 Kivimäki M, Feldt T, Vahtera J, et al. Sense of coherence and health: evidence from two cross-lagged longitudinal samples. Soc Sc Med 2000;50:583-97.

74 Kalimo R, Pahkin K, Mutanen P, et al. Staying well or burning out at work: work characteristics and personal resources as long-term predictors. Work and Stress 2003;17:109-22.

75 Andershed B, Ternestedt B-M. Development of a theoretical framework describing relatives' involvement in palliative care. J Adv Nurs 2001;34:554-62.

76 Bryant LL, Corbett KK, Kutner JS. In their own words: a model of healthy aging. Soc Sci Med 2001;53:927-41.

77 Mackenzie ER, Rajagopal DE, Meibohm M, et al. Spiritual support and psychological well-being. Older adults' perceptions of the religion and health connection. Alternative Therapies and Health Medicine 2000;6:37-45.

78 Persson $\mathbf{D}$. Aspects of meaning in everyday occupations and relationships to health-related factors. (Doctoral thesis.) Lund: Lund University, Department of clinical neuroscience, Division of occupational therapy, 2001

79 Strang S, Strang P. Spiritual thoughts, coping and "sense of coherence" in brain tumour patients and their spouses. Palliat Med 2001;15:127-34.

80 Kasmani SS, Ow R. Worldviews and resilience in children of divorced families. Asia Pasific Journal of Social Work 2001;11(special issue):37-50

81 Pålsson M-BE, Hallberg IR, Norberg A, et al. Systematic clinical supervision and its effects for nurses handling demanding care situations. Interviews with Swedish district nurses and hospital nurses in cancer care. Cancer Nurs 1994; 17:385-94.

82 Hillert L, Savlin P, Berg AL, et al. Environmental illness-effectiveness of a salutogenic group-intervention programme. Scand J Public Health 2002;30:166-75.

83 Delbar V, Benor DE. Impact of a nursing intervention on cancer patients ability to cope. Journal of Psychosocial Oncology 2001;19:57-75.
84 Csíkszentmihályi M, Csíkszentmihalyi IS. Optimal experience. Psychological studies of flow in consciousness. Cambridge: Cambridge University Press, 1998.

85 Polewka A, Chrostek-Maj J, Kroch S. Psychosocial aspects of the suicidal attempts of Polish females. Archives of Psychiatry and Psychotherapy 2001;3:51-60.

86 Berg JE, Brevik Jl. Complaints that predict drop-out from a detoxification and counselling unit. Addict Behav 1998;23:35-40.

87 Hoehn-Anderson K. The relationship between family sense of coherence and family quality of life after illness diagnosis. Collective and consensus views. In, McCubbin HI, Thompson TE, Thompson Al, et al, eds. Stress, coping, and health in families. Sense of coherence and resiliency Thousand Oaks, Sage, 1998:169-87.

88 Sagy S, Antonovsky A. The family sense of coherence and the retirement transition. Journal of Marriage and Family 1992;54:983-94.

89 Sagy S. Effects of personal, family, and community characteristics on emotional reactions in a stress situation. Youth and Society 1998;29:311-30.

90 Sagy S, Dotan N. Coping resources of maltreated children in the family: a salutogenic approach. Child Abuse Negl 2001;25:1463-80.

91 Sagy S. Moderating factors explaining stress reactions: comparing chronicwithout-acute-stress and chronic-with-acute-stress situations. J Psychol 2002;136:407-19.

92 Margalit M, Efrati M. Loneliness, coherence and companionship among children with learning disorder. Educational Psychology 1996;16:69-80.

93 Margalit M, Raviv A, Ankonina DB. Coping and coherence among parents with disabled children. Journal of Clinical Child Psychology 1992;21:202-9.

94 Vinson JA. Children with asthma: initial development of the child resilience model. Pediatr Nurs 2002;28:149-58.

95 Bowen GL, Richman JM, Brewster A, et al. Sense of school coherence, perceptions of danger at school, and teacher support among youth at risk of school failure. Child and Adolescent Social Work Journal 1998;15:273-86.

96 Nash JK. Neighborhood effects on sense of school coherence and educational behavior in students at risk of school failure. Children and Schools 2002;24:73-89.

97 Agardh EE, Ahlbom A, Andersson T, et al. Work stress and low sense of coherence is associated with type 2 diabetes in middle-aged Swedish women. Diabetes Care 2003:26:719-24.

98 Antrila T, Poikolainen K, Uutela A, et al. Structure and determinants of worrying among adolescent girls. Journal of Youth Studies 2000;3:49-60.

99 Jahnsen R, Villien L, Stanghelle JK, et al. Coping potential and disabilitysense of coherence in adults with cerebral palsy. Disabil Rehabil 2002;24:511-18.

100 Lundberg O, Nyström Peck M. Sense of coherence, social structure and health. Evidence from a population survey in Sweden. Eur I Public Health 1994:4:252-7.

101 Lundberg O, Nyström Peck M. A simplified way of measuring sense of coherence. Experiences from a population survey in Sweden. Eur J Public Health 1995;5:56-9.

102 Schumann A, Hapke U, Meyer C, et al. Measuring sense of coherence with only three items: a useful tool for population surveys. $\mathrm{Br} J$ Health Psychol 2003;8:409-21.

103 Surtees $\mathrm{P}$, Wainwright $N$, Luben $R$, et al. Sense of coherence and mortality in men and women in the EPIC-Norfolk United Kingdom prospective cohort study. Am J Epidemiol 2003;158:1202-9.

104 Niemelä M. Koherenssin tunne ja työmarkkina-asema. Sosiaalilääketieteellinen Aikakauslehti 2002;39:184-91

105 Andersen S, Berg JE. The use of a sense of coherence test to predict drop-out and mortality after residential treatment of substance abuse. Addiction Research and Theory 2001:9:239-51.

106 Berg JE. Use of a sense of coherence test and Hopkins Symptom Checklist to predict completion on stay in a postdetoxification counseling unit. American Journal on Addictions 1996;5:327-33.

107 Berg JE, Andersen S, Brevik JI, et al. Drug addiction as a lifestyle. Scandinavian Journal of Social Welfare 1996;5:30-4.

108 Berg JE, Andersen SBA. Mortality 5 years after detoxification and counseling as indicated by psychometric tests. Substance Abuse 2001;22:1-10.

109 Berg JE, Andersen S. Sense of coherence evaluated by treatment counsellors and substance abusers as an indication of length of stay. European Addiction Research 1997;3:99-102.

110 Cheung P, Spears G. Psychiatric morbidity among New Zealand Cambodians: the role of psychosocial factors. Soc Psychiatry Psychiatr Epidemiol 1995;30:92-7.

111 Hall-Lord ML, Larsson G, Steen B. Chronic pain and distress in older people: a cluster analysis. International Journal of Nursing Practice 1999;5:78-85.

112 Hall-Lord ML, Steen B, Larsson G. Postoperative experiences of pain and distress in elderly patients. An explorative study. Aging Clinical and Experimental Research 1999;11:73-82.

113 Johansson I, Hamrin E, Larsson G. Evaluation of the prognostic value of the health assessment form among patients clinically ready for discharge. Journal of Nursing Management 1994;2:77-85.

114 Kivimäki M, Vahtera J, Thomson L, et al. Psychosocial factors predicting employee sickness absence during economic decline. J Appl Psychol 1997:82:858-72.

115 Larsson G, Johansson I, Hamrin E. Sense of coherence among elderly somatic patients: predictive power regarding future needs of care. Journal of Nursing Management 1995;3:307-11.

116 Larsson G, Kallenberg K, Setterlind S, et al. Health and loss of a family member: impact of sense of coherence. Int J Health Sci 1994;5:5-11.

117 Midanik LT, Soghikian K, Ransom U, et al. Alcohol problems and sense of coherence among older adults. Soc Sci Med 1992;34:43-8. 
118 Vahtera J, Pentti J, Uutela A. The effect of objective job demands on registered sickness absence spells; do personal, social and job-related resources act as moderators? Work and Stress 1996;10:286-308.

119 Hellström C, Jansson B, Carlsson SG. Subjective future as a mediating factor in the relation between pain, pain-related distress and depression. European Journal of Pain 1999;3:221-33.

120 Eriksson N-G, Lundin T. Early traumatic stress reactions among Swedish survivors of the m/s Estonia disaster. Br J Psychiatry 1996;169:713-16.

121 Strümpfer DJW. The relation between religious motivation and work-related variables among agricultural workers. South African Journal of Psychology 1997;27:134-43.

122 Ing JD, Reutter L. Socioeconomic status, sense of coherence and health in Canadian women. Can J Public Health 2003:94:224-8.

123 Johnsen MHS, Soviknes I, Torsheim T. Salutogenic coping resources and school-related stress: a prospective study of reciprocal effects. (Mestringsressurser og opplevd skolerelatert stress: en prospektiv studie av giensidige sammenhenger). Tidsskrift for Norsk Psykologforening 2001;38:821-8

124 Nyamathi AM. Relationship of resources to emotional distress, somatic complaints, and high-risk behaviors in drug recovery and homeless minority women. J Health Care Poor Underserved 1992;3:93-106.

125 Nyamathi A. Comparative study of factors relating to HIV risk level of black homeless women. J Acquir Immune Defic Syndr 1992;5:222-8.

126 Strümpfer DJW. Sense of coherence, negative affectivity, and general health in farm supervisors. Psychol Rep 1997;80:963-6.

127 Suominen S. Perceived health and life control. A theoretical review and empirical study about the connections between health and life control determined according to the strength of the sense of coherence. (Doctoral thesis.) Jyväskylä: STAKES - National Research and Development Centre for Welfare and Health, Research Reports 26, 1993.

128 Suominen S, Blomberg $\mathrm{H}$, Helenius $\mathrm{H}$, et al. Sense of coherence and health-does the association depend on resistance resources? A study of 3115 adults in Finland. Psychology and Health 1999;14:937-48.

129 Vuori J. Pre-employment antecedents of health resources, job factors and health risk behaviour in men and women. Work and Stress 1994;8:263-77.

130 Chamberlain K, Zika S. Stability and change in subjective well-being over short time periods. Social Indicators Research 1992;26:101-17.

131 Charlton BG. Senescence, cancer and "endogenous parasites": a salutogenic hypothesis. J R Coll Physicians Lond 1996;30:10-12.

132 Neikrug $S$. Worrying about a frightening old age. Aging and Mental Health 2003;7:326-33.

133 Frenz AW, Carey MP, Jorgensen RS. Psychometric evaluation of Antonovsky's sense of coherence scale. Psychological Assessment 1993;5: 145-53.

134 Gana K. Is sense of coherence a mediator between adversity and psychological well-being in adults? Stress and Health 2001;17:77-83.

135 Büchi S, Sensky T, Allard S, et al. Sense of coherence-a protective factor for depression in rheumatoid arthritis. J Rheumatol 1998;25:869-75.

136 Flannery R, Perry C, Penk WE, et al. Validating Antonovsky's sense of coherence scale. J Clin Psychol 1994;50:575-7.

137 Larsson G, Kallenberg K. Dimensional analysis of sense of coherence using structural equation modelling. European Journal of Personality 1999; 13:51-61.

138 Germano D, Misajon R, Cummins RA. Quality of life and sense of coherence in people with arthritis. Journal of Clinical Psychology in Medical Settings 2001;8:253-61.

139 Feldt T. Sense of coherence. Structure, stability and health promoting role in working life. Jyväskylä studies in education, psychology and social research 158. (Doctoral thesis). Jyväskylä: University of Jyväskylä, 2000.
140 Bothmer von M, Fridlund B. Self-rated health among university students in relation to sense of coherence and other personality traits. Scandinavian Journal of Caring Science 2003;17:347-57.

141 Cohen L, Morrisson K, Manion L. Research methods in education. London: Falmer Press, 2000.

142 Gibson LM, Cook MJ. Neuroticism and sense of coherence. Psychol Rep 1996;79:343-9.

143 Snekkevik H, Anke AG, Stanghelle JK, et al. Is sense of coherence stable after multiple trauma? Clinical Rehabilitation 2003;17:443-53.

144 Forsberg C, Björvell H, Cedermark B. Well-being and its relation to coping ability in patients with colo-rectal and gastric cancer before and after surgery. Scandinavian Journal of Caring Science 1996;10:35-44.

145 Cederfjäll C, Langius-Eklöf A, Lidman K, et al. Gender differences in perceived health-related quality of life among patients with HIV infection. AIDS Patient Care and STDS 2001;15:31-9.

146 Ingram KM, Corning AF, Schmidth LD. The relationship of victimization experiences to psychological well-bering among homeless women and lowincome housed women. Journal of Counseling Psychology 1996:43:218-27.

147 Friborg O, Hjemdal O, Rosenvinge $\mathrm{JH}$, et al. A new rating scale for adult resilience: what are the central protective resources behind healthy adjustment? International Journal of Methods in Psychiatric Research 2003;12:65-76.

148 Florian V, Dangoor N. Personal and familial adaptation of women with severe physical disabilities: a further validation of the double $A B C X$ model. Journal of Marriage and Family 1994;56:735-46.

149 Greenhalg T. How to read a paper. Statistics for non-statistician II: significant relations and their piffalls. BMJ 1997:315:422-5.

150 Ristner G, Andersson R, Johansson LM, et al. Sense of coherence and lack of control in relation to outcome after orthopaedic injuries. Injury 2000;31:751-6.

151 Ray EC, Nickels MW, Sayeed S, et al. Predicting success after gastric bypass: the role of psychosocial and behavioral factors. Surgery 2003; 134:555-64.

152 Bengtsson-Tops A, Hansson L. The validity of Antonovsky's sense of coherence measure in a sample of schizophrenic patients living in the community. J Adv Nurs 2001;33:432-8.

153 Melin R, Fugl-Meyer AR. On prediction of vocational rehabilitation outcome at a Swedish employability institute. Journal of Rehabilitation Medicine 2003;35:284-9.

154 Santavirta N, Björvell B, Konttinen YT, et al. Sense of coherence and outcome of anterior low-back fusion. A 5- to 13-year follow-up of 85 patients. Arch Orthopediatr Trauma Surg 1996;115:280-5.

155 Hittner JB. Novel methods for analyzing multifaceted personality scales: sense of coherence and depression as an example. J Psychol 2000;134:199-210

156 Nesbitt BJ, Heidrich SM. Sense of coherence and illness appraisal in older women's quality of life. Res Nurs Health 2000;23:25-34.

157 Lewis JS. Sense of coherence and the strengths perspective with older persons. Journal of Gerontological Social Work 1996;26:99-112.

158 Cronbach L. Coefficient alpha and the internal structure of tests. Psychometrika 1951;16:297-334.

159 Thorell-Ekstrand I, Biörvell H. Preparedness for clinical nursing education. Scandinavian Journal of Caring Science 1993;8:17-24.

160 Hawley DJ, Wolfe F, Cathey MA. The sense of coherence questionnaire in patients with rheumatic disorders. J Rheumatol 1992;19:1912-18.

161 Takkinen S, Ruoppila I. Meaning in life in three samples of elderly persons with high cognitive functioning. Int J Aging Hum Dev 2001;53:51-73.

162 Clark LA, Watson D. Constructing validity: basic issues in objective scale development. Psychological Assessment 1995;7:309-19. 